Obere Extremität 2019 · 14:197-201 https://doi.org/10.1007/s11678-019-0535-z Received: 21 March 2019

Accepted: 11 July 2019

Published online: 15 August 2019

(c) The Author(s) 2019

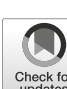

\section{Introduction}

It is well known that loosening of the glenoid component is one of the major concerns of total shoulder arthroplasty, especially in the long run $[3,7,8]$. Several studies highlighted this topic in recent years, and there is a clear trend toward superior long-term outcomes of cemented glenoid components compared to uncemented metal-backed implants $[4,12$, 20]. Although revision rates for loosened glenoid components are relatively low in most studies, radiographic findings are disturbing, especially after 10 years of follow-up [3, 17, 24, 25]. Radiographic loosening rates up to $73 \%$ after a minimum follow-up of 15 years have been described [14].

Several risk factors leading to loosening of the glenoid have been described [24]; however, no detailed information is available on the percentages based on a large cohort for each patient-related risk factor, implant-related risk factor, or risk factors related to surgical technique.

The aim of this multicenter study was therefore to analyze the above-mentioned risk factors in a large cohort of patients treated with a 3rd-generation cemented total shoulder arthroplasty with a keeled glenoid component.

\author{
Patric Raiss ${ }^{1}$ Markus Loew ${ }^{2}$ Thomas Bruckner ${ }^{3} \cdot$ Luc Favard $^{4} \cdot$ Pascal Boileau $^{5}$. \\ Gilles Walch ${ }^{6}$ \\ ${ }^{1}$ OCM Klinik München, Munich, Germany \\ ${ }^{2}$ Department of Shoulder and Elbow Surgery, ATOS Clinic Heidelberg, Heidelberg, Germany \\ ${ }^{3}$ Institute of Medical Biometry and Informatics, University of Heidelberg, Heidelberg, Germany \\ ${ }^{4}$ Orthopédie 1, CHU Trousseau, Tours cedex, France \\ ${ }^{5}$ Hôpital Pasteur 2, Nice, France \\ ${ }^{6}$ Centre Orthopédique Santy, Lyon, France
}

\title{
Risk factors for loosening of cemented glenoid components in anatomical shoulder arthroplasty
}

\section{Methods}

Five centers specializing in shoulder surgery participated in this study. Portions of this data have recently been used in published articles [14, 15, 18, 24, 26]. However, the current analysis is unique and has not previously been published. All cases treated between September 1991 and October 2004 were included in this study if the following inclusion criteria were all fulfilled:

1. Diagnosis of primary osteoarthritis of the glenohumeral joint

2. Absence of rotator cuff tears

3. A minimum follow-up of 5 years

4. Treatment with the same 3rd-generation total shoulder arthroplasty with a cemented keeled glenoid component

5. Complete clinical and radiographic data

During this period, 565 total shoulder arthroplasties were performed in the five centers. Ninety-four (16.8\%) had to be excluded as they were lost to follow-up $(n=61)$, did not want to participate in the study $(n=15)$, or had incomplete preoperative data $(n=18)$. The study cohort consisted of 471 cases.

Mean follow-up was 8.1 (range, 5-20) years. Mean follow-up of patients with a flat-back glenoid component was 117 (25-219) months. Mean follow-up of patients with a convex-back glenoid com- ponent was 87 (24-152) months. There were 318 women and 153 men. Mean age at the time of arthroplasty was 68 $68 \pm 8.6$ (range 35-90) years. The dominant shoulder was treated in 294 cases and the nondominant in 177 .

Surgical technique has been extensively described in the past [14].

The same 3rd-generation total shoulder arthroplasty system was used in all cases (Wright Medical Group N.V., Memphis, TN, USA). The humeral stem as well as the glenoid component were cemented. A flat-back glenoid component was used in the first 186 cases and a convex-backed component in the following 285 cases.

Glenoid morphology according to Walch et al. [21] was as follows: an A1 glenoid was present in 128 cases, an A2 in 128 , a $\mathrm{B} 1$ in 94 , a $\mathrm{B} 2$ in 117 , and a $\mathrm{C}$ in 4 .

Preparation of the glenoid was different among surgeons. Some surgeons preferred only a slight reaming and protection of the subchondralbone layer, and some preferred to take down the bone layer. A slight reaming on the glenoid side with protection of the subchondral bone was done in 103 cases, and an aggressive reaming with removal of the subchondral bone was done in 325 cases. In 43 cases, the kind of reaming was not clear, so these cases were excluded from analysis.

Clinical parameters using the Constant score with its subgroups and active 


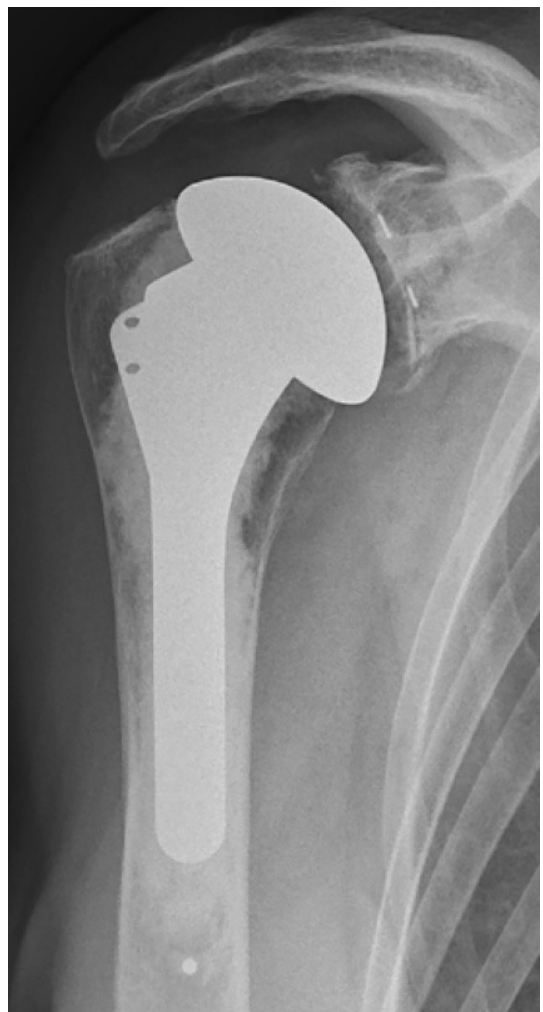

Fig. $1 \Delta$ Anteroposterior radiograph of a right shoulder 8 years after surgery showing a wellfixed humeral and glenoid component. The glenoid component has only a slight radiolucent line at the inferior part

shoulder flexion and external rotation were documented and were published in the past [24-26]. Preoperative radiographs of the affected shoulders in two planes (anterior-posterior and axillary views) as well as computed tomography $(n=405)$ or magnetic resonance imaging $(n=66)$ scans were available. Radiolucent lines around the glenoid components were analyzed according to the score of Mole et al. ([10]; - Fig. 1). Additionally, loosening of the glenoids was classified by migration or subsidence of the implants.

Fatty infiltration of the rotator cuff muscles was classified according to the method of Goutallier et al. [6].

A risk analysis for glenoid loosening was performed for the following factors: gender, age, hand dominance, glenoid morphology according to Walch et al. [21], reaming on the glenoid side (aggressive reaming with destruction of the subchondral bone versus slight reaming with protection of the subchondral bone),

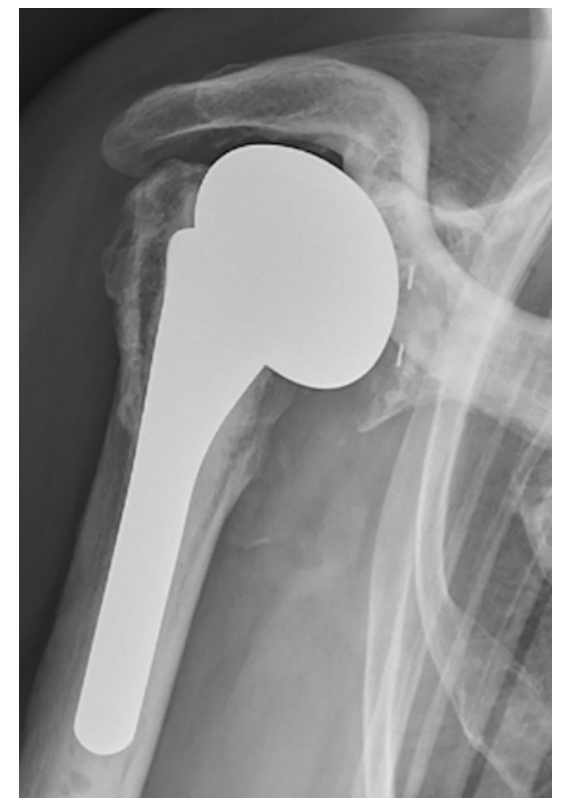

Fig. $2 \Delta$ Anteroposterior radiograph of a right shoulder 12 years after surgery showing a medial subsidence of the cemented glenoid component and a cranial migration of the humeral head

glenohumeral mismatch, glenoid component design, and fatty degeneration of the supraspinatus, infraspinatus, and subscapularis muscles according to the classification of Goutallier et al. [6].

\section{Statistics}

The empirical distribution of continuous data was reported with mean and standard deviation (range), with absolute and relative frequencies in the case of categorical data. Possible risk factors for glenoid loosening were evaluated using multivariable binary logistic regression.

\section{Results}

The mean radiolucent line score was $8.3 \pm 6.7$ (range 0-18) points at final follow-up. A total of 137 glenoid components (29.1\%) were radiographically judged to be at risk for loosening (• Fig. 2). The overall revision rate in this cohort was $8.7 \%(n=41)$. There were 17 cases with glenoid loosening that were revised with an autograft from the iliac crest and a new cemented keeled glenoid, 10 cases that were revised to a reverse shoulder arthroplasty, 6 cases with removal of a loosened glenoid component,
4 cases with removal of the complete implant, 4 cases with soft-tissue revisions, and 2 cases with periprosthetic humeral fractures. No influence on radiographic glenoid loosening was found for patient age at surgery, gender, hand dominance, preparation technique on the glenoid side, or fatty degeneration of the rotator cuff $(p>0.067)$.

The following risk factors for glenoid component loosening were detected:

1. Excessive reaming on the native glenoid with removal of subchondral bone led to a 3.7-fold higher risk for glenoid component loosening $(p<0.001)$.

2. A glenohumeral mismatch $<6 \mathrm{~mm}$ was associated with higher radiographic loosening rates $(p<0.03)$, and the risk increased by $19 \%$ with every single millimeter of less mismatch.

3. The use of a flat-back glenoid component led to a 3.1-fold higher risk for radiographic loosening compared to convex-back glenoids $(p<0.001)$.

4. B2 glenoids had a higher risk for radiographic loosening compared to A1 (2.3-fold), A2 (3.6-fold), and B1 (2.7-fold) glenoids $(p<0.001)$.

\section{Discussion}

Radiographic loosening of a cemented polyethylene glenoid component frequently occurs in the long term and is one of the main reasons for revision surgery $[8,13,14,24]$.

Several risk factors have been described in the literature, and we aimed to analyze some of these in a multicenter investigation in a homogenous cohort of patients with primary osteoarthritis. Interestingly, there were many patientspecific factors, such as hand dominance and fatty infiltration of rotator cuff muscles, that did not influence the occurrence of glenoid component loosening.

Walch et al. described in a retrospective multicentric study in 2012 the influence of reaming on the occurrence of radiographic subsidence of cemented keeled glenoid components [24]. They found that aggressive reaming on the glenoid side with taking down of the sub- 
Obere Extremität 2019 · 14:197-201 https://doi.org/10.1007/s11678-019-0535-z

(c) The Author(s) 2019

P. Raiss · M. Loew · T. Bruckner · L. Favard · P. Boileau · G. Walch

\section{Risk factors for loosening of cemented glenoid components in anatomical shoulder arthroplasty}

\section{Abstract}

Introduction. Several risk factors leading to loosening of the glenoid have been described; however, there is no detailed information available on the exact numbers or percentages for each patient-related risk factor, implantrelated risk factor, or risk factors related to surgical technique.

Therefore, the aim of this multicenter study was to analyze these risk factors in a large cohort of patients treated with a 3rd-generation cemented total shoulder arthroplasty.

Methods. Four-hundred seventy-one shoulder arthroplasties with a mean followup of 8.1 years were included. There were 318 women and 153 men. The mean age at the time of arthroplasty was 68 (range 35-90) years. The dominant shoulder was treated in 294 cases and the nondominant in 177. The following risk factors for loosening of the cemented keeled glenoid component were examined: gender, age, hand dominance, glenoid morphology, reaming on the glenoid side (reaming down the complete subchondral bone layer), glenohumeral mismatch, glenoid component design, and fatty degeneration of the rotator cuff.

Results. No influence on radiographic glenoid loosening was found for patient age at surgery, gender, hand dominance, preparation technique on the glenoid side, or fatty degeneration of the rotator cuff $(p>0.067)$. Excessive reaming on the native glenoid led to a 3.7-fold higher risk for glenoid component loosening $(p<0.001)$. A glenohumeral mismatch $<6 \mathrm{~mm}$ was associated with higher radiographic loosening rates $(p<0.03)$. The use of a flat-back glenoid component led to a 3.1-fold higher risk for radiographic loosening compared to convex-back glenoids
( $p<0.001)$. B2 glenoids had a higher risk for radiographic loosening compared to $A 1$ (2.3fold), A2 (3.6-fold), and B1 (2.7-fold) glenoids $(p<0.001)$.

Conclusion. Based on a large and homogenous cohort of patients, this study has shown several risk factors for loosening of a cemented glenoid component in the midterm and long term. The loosening rates of cemented keeled glenoid components in primary osteoarthritis could possibly be reduced by optimizing surgical technique, implant configuration, and patient selection. Further long-term studies are necessary to confirm these findings.

Keywords

Shoulder arthroplasty $\cdot$ Reaming $\cdot$ Arthroplasty. Glenohumeral mismatch. Shoulder replacement

\section{Risikofaktoren für die Glenoidlockerung zementierter Pfannen in der anatomischen Schulterendoprothetik}

\section{Zusammenfassung}

Einleitung. Obwohl unterschiedliche Risikofaktoren für Glenoidlockerungen in der Vergangenheit beschrieben wurden, gibt es für Patienten-, Implantat- oder Operationstechnik-spezifische Risikofaktoren keine bezifferten Daten. Ziel dieser multizentrischen Studie war es, diese Faktoren an einem großen Kollektiv, welches mit anatomischen Schulterprothesen der 3 . Generation versorgt wurde, zu untersuchen.

Methoden. Es wurden 471 Schultertotalprothesen mit einem mittleren Nachuntersuchungszeitraum von 8,1 Jahren in die Studie eingeschlossen. Die Gruppe bestand aus 318 Frauen und 153 Männern. Das mittlere Alter zum Zeitpunkt der Operation betrug 68 Jahre. Die dominante Schulter wurde in 294 Fällen und die nichtdominante in 177 Fällen versorgt. Die folgenden potenziellen Risikofaktoren für die Glenoidlockerung wurden im Einzelnen untersucht: Geschlecht, Alter bei Operation, dominante Seite, Glenoidmorphologie, Fräsung des subchondralen Knochens an der Pfannenseite, glenohumerales Mismatch, Prothesendesign und die fettige Degeneration der Rotatorenmanschettenmuskeln. Ergebnisse. Kein Einfluss auf eine Lockerung wurde für folgende Faktoren gefunden: Alter des Patienten zum Zeitpunkt der Operation, Geschlecht, dominante Seite und fettige Degeneration der Rotatorenmanschette $(p<0,067)$. Ein aggressives Fräsen des subchondralen Knochens am Glenoid führte zu einem 3,7-fach erhöhten Risiko für Glenoidlockerungen $(p<0,001)$. Ein glenohumerales Mismatch $<6 \mathrm{~mm}$ war mit erhöhten Lockerungsraten verbunden $(p<0,03)$. Flat-back-Glenoide hatten ein 3,1-fach erhöhtes Risiko für Lockerungen im Vergleich zu Convex-back-Glenoiden $(p<0,001)$. B2-Glenoide hatten ein höheres
Lockerungsrisiko verglichen mit A1- (2,3-fach), A2- (3,6-fach) und B1-Glenoiden (2,7-fach; $p<0,001)$.

Schlussfolgerung. In dieser Studie wurden anhand eines großen und homogenen Patientenkollektivs exakte Risikofaktoren für die Lockerung der zementierten Glenoidkomponente für den mittel- bis langfristigen Verlauf beschrieben. Die Lockerungsraten könnten potenziell durch eine Optimierung der Operationstechnik, Implantatkonfiguration und Patientenselektion verringert werden. Zur Bestätigung dieser Ergebnisse sind weitere langfristige Studie notwendig.

Schlüsselwörter

Schulterarthroplastik · Abtragung - Endoprothetik - Glenohumerales Mismatch . Schulterprothese chondral bone layer leads to significantly higher rates of radiographic subsidence. Therefore, the authors recommend performing a bone-preserving reaming technique whenever possible. In the present study, we were able to show that aggressive reaming is associated with a 3.7 -fold higher risk for glenoid components in the midterm and long term. Based on the findings of Walch et al., new glenoid component designs and reamers were developed with varying backside radiuses of curvature to match the patient's anatomy and to adapt the implant to the native bone and not vice versa. Promising shortterm results of those implant concepts have been published, but no long-term data are available yet $[2,16]$.

Again, Walch and colleagues have already described how glenohumeral mismatch seems to play an important 
role in the occurrence of radiographic lucent lines of cemented components [22]. They found that a mismatch of $<5.5 \mathrm{~mm}$ leads to significantly worse radiolucent line scores compared to higher mismatches. Their conclusion was that the ideal mismatch should be between $6 \mathrm{~mm}$ and $10 \mathrm{~mm}$ in order to decrease radiographic lucency. We showed the same relationship and were able to exactly define the percentage of increased risk with each millimeter of mismatch. These findings may have an influence on the development of new implants as well as on a slight radiolucent line at the inferior part ways for surgeons to find the correct combination of humeral head and glenoid implants intraoperatively and during the preoperative planning process.

Controversial data have been published regarding the radiographic outcomes of flat-back versus convex-back cemented glenoid components. Convex-back components were introduced in order to minimize subchondral bone removal and to adapt the implant more closely to the bone. However, the same study group was examined at a mean follow-up of 10 years, and Collin and colleagues showed that there was no longer any difference between the two groups [1]. In our study with a substantially higher number of patients, we found that the occurrence of radiolucent lines was 3.1-fold higher when using flat-back components. However, we must mention that the mean follow-up duration of the flat-back components in this study was longer compared to that of the convexback components. Szabo et al. demonstrated in the short term fewer radiolucent lines by using convex-back cemented keeled components [19].

The eccentric wear of the glenoid in osteoarthritis is a well-known and challenging condition. Multiple articles have been published in the past showing the increased risk of glenoid component loosening in cases of eccentric glenoid erosion $[5,11]$. Because of this fact, many surgeons tend to move toward reverse shoulder arthroplasty in cases of severe glenoid wear [9]. In the current study, we were able to show for the first time that the risk of radiographic glenoid loosen- ing in B2 glenoids is between 2.3 and 3.6 times higher compared to concentric glenoids (A1 and A2). Walch et al. have demonstrated that a humeral head subluxation of more than $80 \%$ and an intermediate glenoid retroversion of more than $27^{\circ}$ is associated with a $50 \%$ risk of complications in the midterm follow-up, especially for glenoid component loosening [23]. Although the data of the current study support these findings, future investigations are necessary to find a true cut-off when an anatomical replacement will fail and a reverse shoulder arthroplasty may be indicated.

\section{Limitations}

This study has several limitations. It is a retrospective case series without a control group. Surgical technique has changed over the years, which may have influenced the results. Multiple surgeons were involved and surgical technique as well as rehabilitation protocols may have varied slightly. However, it is a very homogenous study population, and to our knowledge, it is the first trial showing exact risk numbers for glenoid component loosening.

\section{Practical conclusions}

\section{- Based on a large and homogenous cohort of patients, this study has shown several risk factors for loosen- ing of cemented glenoid component in the midterm and long term. \\ - The loosening rates of cemented keeled glenoid components in pri- mary osteoarthritis could possibly be reduced by optimizing surgical technique, implant configuration, and patient selection. \\ - Further long-term studies are neces- sary to confirm these findings.}

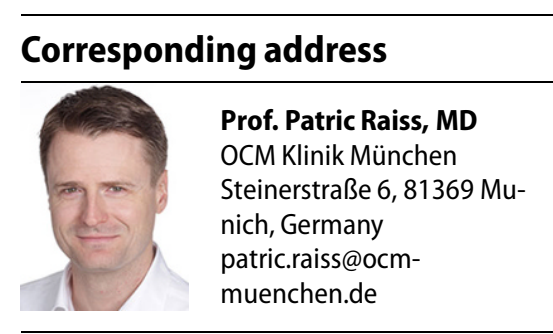

\section{Compliance with ethical guidelines}

Conflict of interest P. Raiss, M. Loew, L. Favard, P. Boileau, and G. Walch are paid consultants for Wright Medical Inc. M. Loew, P. Boileau, and G. Walch receive royalties from Wright Medical Inc. not related to this topic. T. Bruckner declares that he has no competing interests.

The Declaration of Helsinki was respected. This study has an institutional review board approval from the Centre Orthopédique Santy, Lyon, France. A written consent form was completed for all patients. All procedures performed in studies involving human participants or on human tissue were in accordance with the ethical standards of the institutional and/or national research committee and with the 1975 Helsinki declaration and its later amendments or comparable ethical standards. Informed consent was obtained from all individual participants included in the study.

Open Access. This article is distributed under the terms of the Creative Commons Attribution 4.0 International License (http://creativecommons.org/licenses/by/ 4.0/), which permits unrestricted use, distribution, and reproduction in any medium, provided you give appropriate credit to the original author(s) and the source, provide a link to the Creative Commons license, and indicate if changes were made.

\section{References}

1. Collin P, Tay AK, Melis B, Boileau P, Walch G (2011) A ten-year radiologic comparison of twoall polyethylene glenoid component designs: a prospective trial. J Shoulder Elbow Surg 20:1217-1223

2. Dauzere F, Arboucalot M, Lebon J, Elia F, Bonnevialle N, Mansat P (2017) Evaluation of thirty eight cemented pegged glenoid components with variable backside curvature: two-year minimum follow-up. Int Orthop 41:2353-2360. https://doi. org/10.1007/s00264-017-3635-7

3. Fox TJ, Cil A, Sperling JW, Sanchez-Sotelo J, Schleck CD, Cofield RH (2009) Survival of the glenoid component in shoulder arthroplasty. J ShoulderElbow Surg 18:859-863

4. Fucentese SF, Costouros JG, Kuhnel SP, Gerber C (2010) Total shoulder arthroplasty with an uncemented soft-metal-backed glenoid component. J ShoulderElbow Surg 19:624-631

5. Gerber C, Costouros JG, Sukthankar A, Fucentese SF (2009) Static posterior humeral head subluxation and total shoulder arthroplasty. J Shoulder Elbow Surg 18:505-510. https://doi.org/10.1016/j.jse. 2009.03.003

6. Goutallier D, Postel JM, Bernageau J, Lavau L, Voisin MC (1994) Fatty muscle degeneration in cuff ruptures. Pre- and postoperative evaluation by $C T$ scan. Clin Orthop Relat Res 304:78-83

7. Kilian CM, Press CM, Smith KM, O'Connor DP, Morris BJ, Elkousy HA et al (2017) Radiographic and clinical comparison of pegged and keeled glenoid components using modern cementing techniques: midterm results of a prospective randomized study. JShoulder Elbow Surg. https:// doi.org/10.1016/j.jse.2017.07.016

8. McLendon PB, Schoch BS, Sperling JW, SanchezSotelo J, Schleck CD, Cofield RH (2017) Survival of the pegged glenoid component in shoulder 
arthroplasty: part II.JShoulderElbow Surg. https:// doi.org/10.1016/j.jse.2016.12.068

9. Mizuno N, Denard PJ, Raiss P, Walch G (2013) Reverse total shoulder arthroplasty for primary glenohumeral osteoarthritis in patients with a biconcave glenoid. J Bone Joint Surg Am 95:1297-1304. https://doi.org/10.2106/JBJS.L. 00820

10. Mole D, Roche O, Riand N, Levigne C, Walch G (1999) Cemented glenoid components: results in osteoarthritis and rheumatoid arthritis. Springer, Heidelberg, New York, Barcelona, Hong Kong, London, Milan, Paris, Singapore, Tokyo

11. Nicholson GP, Cvetanovich GL, Rao AJ, O'Donnell P (2017) Posterior glenoid bone grafting in total shoulderarthroplasty for osteoarthritis with severe posterior glenoid wear. J Shoulder Elbow Surg 26:1844-1853. https://doi.org/10.1016/j.jse.2017. 03.016

12. Papadonikolakis A, Matsen FA 3rd (2014) Metalbacked Glenoid components have a higher rate of failure and fail by different modes in comparison with all-polyethylene components: a systematic review. J Bone Joint Surg Am 96:1041-1047. https://doi.org/10.2106/JBJS.M.00674

13. Papadonikolakis A, Neradilek MB, Matsen FA 3rd (2013) Failure of the glenoid component in anatomic total shoulder arthroplasty: a systematic review of the English-language literature between 2006 and 2012. J Bone Joint Surg Am 95:2205-2212. https://doi.org/10.2106/JBJS.L. 00552

14. Raiss P, Bruckner T, Rickert M, Walch G (2014) Longitudinal observational study of total shoulder replacements with cement: fifteen to twenty-year follow-up. J Bone Joint Surg Am 96:198-205. https://doi.org/10.2106/JBJS.M.00079

15. Raiss P, Edwards TB, Deutsch A, Shah A, Bruckner T, Loew M et al (2014) Radiographic changes around humeral components in shoulder arthroplasty. J Bone Joint Surg Am 96:e54. https://doi.org/10. 2106/JBJS.M.00378

16. Raiss $P$, Godeneche $A$, Wittmann T, Schnetzke $M$, Bruckner T, Neyton L et al (2018) Short-term radiographic results of a cemented polyethylene keeled glenoid component with varying backside radiuses of curvature. J Shoulder Elbow Surg 27:839-845. https://doi.org/10.1016/j.jse.2017 10.026

17. Raiss $P$, Schmitt M, Bruckner T, Kasten P, Pape $G$, Loew M et al (2012) Results of cemented total shoulder replacement with a minimum follow-up of ten years. J Bone Joint Surg Am 94:e1711-1710

18. Sowa B, Bochenek M, Braun S, Zeifang F, Kretzer JP, Bruckner T et al (2018) Replacement options for the B2 glenoid in osteoarthritis of the shoulder: a biomechanical study. Arch Orthop Trauma Surg. https://doi.org/10.1007/s00402-018-2915-z

19. Szabo I, Buscayret F, Edwards TB, Nemoz C, BoileauP,Walch G (2005) Radiographic comparison of flat-back and convex-back glenoid components in total shoulder arthroplasty. J Shoulder Elbow Surg 14:636-642

20. Taunton MJ, Mclntosh AL, Sperling JW, Cofield RH (2008) Total shoulder arthroplasty with a metalbacked, bone-ingrowth glenoid component. Medium to long-term results. J Bone Joint Surg Am 90:2180-2188

21. Walch G, Badet R, Boulahia A, Khoury A (1999) Morphologic study of the glenoid in primary glenohumeral osteoarthritis. J Arthroplasty 14:756-760

22. Walch G, Edwards TB, Boulahia A, Boileau P, Mole D, Adeleine $P$ (2002) The influence of glenohumeral prosthetic mismatch on glenoid radiolucent lines: results of a multicenter study. J Bone Joint Surg Am 84-A:2186-2191

23. Walch G, Moraga C, Young A, CastellanosRosas J (2012) Results of anatomic nonconstrained prosthesis in primary osteoarthritis with biconcave glenoid. J Shoulder Elbow Surg 21:1526-1533. https://doi.org/10.1016/j.jse.2011.11.030

24. Walch G, Young AA, Boileau P, Loew M, Gazielly D Mole D (2012) Patterns of loosening of polyethylene keeled glenoid components after shoulder arthroplasty for primary osteoarthritis: results of a multicenter study with more than five years of follow-up. JBone Joint Surg Am 94:145-150

25. Walch G, Young AA, Melis B, Gazielly D, Loew M, Boileau P (2011) Results of a convex-back cemented keeled glenoid component in primary osteoarthritis: multicenter study with a followup greater than 5 years. J Shoulder Elbow Surg 20(3):385-394. https://doi.org/10.1016/j.jse. 2010.07.011

26. Young A, Walch G, Boileau P, Favard L, Gohlke F, Loew $M$ et al (2011) A multicentre study of the long-term results of using a flat-back polyethylene glenoid component in shoulder replacement for primary osteoarthritis. J Bone Joint Surg $\mathrm{Br}$ 93:210-216 